\title{
Construção de competências colaborativas para o trabalho em saúde nos estágios curriculares de Odontologia no SUS
}

\author{
José Ricardo Busatto*; Raíssa Carrion Trein*; Eloá Rossoni** \\ * Egresso(a), Curso de Odontologia, Universidade Federal do \\ Rio Grande do Sul \\ ** Doutora em Educação. Professora Associada, \\ Departamento de Odontologia Preventiva e Social, \\ Faculdade de Odontologia, Universidade Federal do Rio \\ Grande do Sul
}

Recebido: 24/07/2019. Aprovado: 12/01/2021.

\begin{abstract}
RESUMO
Com a implementação do Sistema Único de Saúde (SUS), foram necessárias mudanças curriculares que preparassem os profissionais para atuar em equipe na rede de saúde. No início do século XXI passaram a ser implementadas as Diretrizes Curriculares Nacionais (DCN) que trouxeram várias mudanças, dentre as quais destaca-se a inserção do estudante de graduação no SUS. O objetivo desse estudo é analisar as percepções dos egressos do curso de graduação em Odontologia diurno de uma universidade pública do Rio Grande do Sul, acerca da construção de competências colaborativas, durante a formação nos Estágios Curriculares Supervisionados (ECS) no SUS. Trata-se de um estudo de natureza descritiva com análise de dados qualitativos e quantitativos. Inicialmente, 133 egressos, que vivenciaram os ECS entre 2012/1 a 2016/1, responderam a um questionário online com questões abertas e fechadas. Com uma amostra intencional de 14 egressos, que responderam ao questionário, foram realizadas entrevistas semiestruturadas em profundidade. O material quantitativo foi submetido à análise descritiva e o material qualitativo à análise de conteúdo temática. Considerando que os dados quantitativos e qualitativos são complementares, eles foram submetidos a triangulação e os resultados são apresentados em duas unidades de análise: Caracterização, inserção e escolhas profissionais dos egressos e Construção de competências colaborativas. A maioria dos egressos participantes $(67,7 \%)$ são do sexo feminino e estão atuando em Porto Alegre ou região metropolitana $(78,6 \%), 29,1 \%$ deles estão vinculados a serviços públicos de saúde. A satisfação com os ECS é destacada pelos egressos, que os descrevem como indispensáveis para sua formação. Dentre as competências colaborativas construídas por meio dos estágios, o aprendizado de trabalhar em equipe interprofissional é destacado pela maioria dos egressos $(85,3 \%)$, sendo lembrada como fundamental para a atenção integral do usuário. Conclui-se que o curso de Odontologia tem obtido sucesso na formação de profissionais voltados para atuação no SUS, tendo um percentual considerável de egressos vinculados aos serviços públicos de saúde.
\end{abstract}

Descritores: Odontologia Comunitária. Educação em Odontologia. Serviços de Saúde. Educação Baseada em Competências. 


\section{INTRODUÇÃO}

No Brasil, após a Constituição de 1988, que estabelece "a saúde como um direito de todo o cidadão e dever do Estado", foi regulamentado o Sistema Único de Saúde (SUS) e, em 2006, houve a regularização da Política Nacional de Atenção Básica (PNAB), fundamental para $\mathrm{O}$ funcionamento do $\mathrm{SUS}^{1,2}$. O sistema de saúde do país organiza-se em formato de rede com diversos pontos de atenção à saúde que devem funcionar integrados uns aos outros, tendo como vias de acesso as Unidades Básicas de Saúde (UBS) com e sem equipes de Estratégia de Saúde da Família (ESF), que estão intimamente vinculadas às comunidades de suas áreas adstritas. Um ponto importante da Atenção Primária em Saúde (APS) é justamente $o$ trabalho em equipe para a integralidade do cuidado, com equipes multiprofissionais, nas quais estão incluídas as Equipes de Saúde Bucal (ESB) ${ }^{2}$.

Foi nesse contexto que o ensino da odontologia brasileira precisou se reestruturar, para que os cursos de graduação formassem profissionais capazes de atuar no sistema de saúde vigente. $\mathrm{O}$ cirurgião-dentista $(\mathrm{CD})$ até então preparado para o mercado privado e a prática curativa, passou a atuar dentro das comunidades com o compromisso de promover atenção integral à saúde ${ }^{3}$. Com o objetivo de aproximar o Sistema Educacional e o Sistema de Saúde, foram elaboradas as Diretrizes Curriculares Nacionais (DCN) para os cursos de graduação em saúde. A Resolução CNE/CES no.3, em 2002, instituiu as DCN dos Cursos de Graduação em Odontologia, em que estão descritas as seguintes competências gerais a serem desenvolvidas na graduação em Odontologia: Atenção à Saúde; Tomada de Decisão; Comunicação; Liderança; Gestão em Saúde e Educação Permanente. No artigo $3^{\circ}$, que trata do perfil do egresso, é indicado a aptidão para atuação em equipe, de forma interprofissional, interdisciplinar e transdisciplinar ${ }^{4}$.
A proposta do trabalho em equipe iniciou na década de 70, com o advento da Medicina Integral/Comunitária, mas somente voltou a ganhar destaque no país a partir da década de 90, com o advento do SUS. A discussão dos modelos de atenção e de organização do sistema de saúde trouxe à tona a necessidade de mudanças na formação de profissionais de saúde, que era predominantemente uniprofissional para a educação interprofissional (EIP). A partir dos anos 2000, a discussão sobre trabalho em equipe passou a ser associada à prática colaborativa devido ao reconhecimento da necessidade de colaboração entre os profissionais, entre equipes de diferentes serviços e entre setores para o trabalho em rede a fim de enfrentar os problemas de saúde, a fragmentação das ações e do sistema ${ }^{5}$.

A problematização do trabalho no SUS, em especial na APS, deve ser examinada de forma contingencial, conforme as características dos usuários/população adscrita, contexto e condições de trabalho. A organização dos serviços com base na associação do trabalho em equipe e das práticas colaborativas tem avançado na APS, aumentando o acesso e a qualidade da assistência à saúde ${ }^{5}$. No entanto, as condições precárias de trabalho envolvendo vínculos empregatícios provisórios, a quantidade insuficiente de profissionais e a falta de preparo dos profissionais para atuarem no SUS são alguns dos fatores que interferem na dinâmica da atenção à saúde 6 . Segundo a Organização Mundial da Saúde (OMS), por meio da educação interprofissional é possível formar uma força de trabalho colaborativa preparada para as práticas humanizadas de atenção integral à saúde ${ }^{7}$.

$\mathrm{Na}$ última década dos anos 2000, tem ocorrido uma discussão potente na definição do que seja trabalho em equipe, prática colaborativa interprofissional e competências colaborativas. $\mathrm{O}$ trabalho em equipe interprofissional envolve diferentes profissionais de saúde e de outras áreas, que trabalham juntos de forma integrada $e$ 
interdependente a fim de definir e compartilhar objetivos comuns e planejar as ações e os cuidados de saúde ${ }^{5}$.

Para que o trabalho em equipe de fato ocorra, é preciso que os trabalhadores criem uma identidade coletiva, construção que se dá a partir da relação entre pessoas e grupos em um determinado espaço, que passam a organizar seu cotidiano desenvolvendo atividades similares e que se complementam, a partir de um conjunto de valores compartilhados. Um dos desafios é que o trabalho em equipe realmente aconteça na prática, pois ainda é possível ver traços hierárquicos nos serviços de saúde, como diferenciação entre profissionais de grau superior ou nível técnico e superioridade de médicos sobre enfermeiros e outros profissionais. Nesse sentido, a prática colaborativa interprofissional pode reduzir a competição entre os profissionais e equilibrar as relações de poder no cuidado em saúde por meio de parceria e responsabilidade coletiva, reconhecendo a atenção centrada no paciente (ACP) como elemento central das práticas de saúde ${ }^{5}$.

Considerando a complexidade do trabalho em equipe interprofissional na saúde, a Educação Interprofissional (EIP) oferece oportunidades de aprendizado aos estudantes com outros profissionais a fim de desenvolverem competências colaborativas para o trabalho coletivo. A EIP é apontada como uma estratégia educacional importante para propiciar atenção de qualidade e segurança aos pacientes ${ }^{8}$.

Alguns autores definem que competência profissional é a capacidade circunstancial de mobilizar articuladamente habilidades, recursos cognitivos, afetivos e psicomotores para a resolução de uma situação-problema ${ }^{9}$. Por óbvio, os profissionais não têm competência para resolução de todas as situações, o que torna o trabalho em equipe e a construção de competências colaborativas indispensáveis para a prática colaborativa profissional.
As competências essenciais para as práticas interprofissionais colaborativas foram definidas pelo grupo Canadian Interprofessional Health Collaborative em: comunicação interprofissional; cuidado centrado no usuário, na família e na comunidade; entendimento dos papéis profissionais e da dinâmica de funcionamento da equipe; liderança colaborativa e capacidade de resolução de conflitos interprofissionais ${ }^{10}$.

A presença de profissionais com competências colaborativas integrando as equipes é essencial para a atenção integral aos usuários. Embora o objetivo da ESF seja, por meio de equipes multiprofissionais, reorganizar a APS buscando esse cuidado integral e longitudinal dos indivíduos e suas famílias, ainda são encontradas dificuldades para o desenvolvimento dessas competências colaborativas dentro das equipes ${ }^{11}$.

Uma das dificuldades é que os profissionais de saúde continuam sendo formados separadamente para depois trabalharem juntos ${ }^{5}$. A vivência das práticas colaborativas, na maioria das vezes, inicia-se no final do curso durante os estágios de graduação e, algumas vezes, na pósgraduação. Estudo que analisou grupos de estudantes que passaram por cursos de segurança do paciente sob o ponto de vista uniprofissional ou interprofissional observou diferença entre os grupos. Todos dizem ter agregado conhecimento, porém aqueles que fizeram o curso sob a perspectiva interprofissional se sentem mais seguros para $\mathrm{o}$ atendimento ${ }^{12}$.

$\mathrm{O}$ atendimento humanizado e a saúde trabalhada sob preceitos éticos, estão fortemente vinculados à introdução das práticas colaborativas. Estudo que avaliou as percepções dos estudantes, professores e usuários acerca da dimensão ética na formação de graduandos em odontologia apontou críticas oriundas dos estudantes. Eles relatam que apesar dos esforços para incutir os preceitos éticos na sua prática profissional, os professores não praticam aquilo que é proposto, o que aponta a 
necessidade de também preparar quem forma para a EIP. O estudo da ética ainda esbarra em impeditivos, como valores adquiridos pelos estudantes no âmbito familiar e em suas experiências de vida, que muitas vezes determinam as atitudes tomadas pelos mesmos ${ }^{13}$.

O objetivo do presente estudo é analisar as percepções dos egressos do curso diurno de Odontologia acerca da construção de competências colaborativas para a atenção integral do usuário, durante a formação acadêmica nos Estágios Curriculares Supervisionados no SUS. Objetiva-se ainda descrever os aspectos da formação que possibilitaram o desenvolvimento de competências colaborativas para o trabalho em saúde, identificando as contribuições dos estágios nos quesitos liderança colaborativa, comunicação interprofissional, resolução de conflitos e cuidado focado no usuário, na família e na comunidade.

\section{METODOLOGIA}

Este trabalho é um recorte do projeto de pesquisa "Estágios Curriculares de Odontologia no SUS: Implicações nas Escolhas Profissionais e no Aprendizado de Competências para o Trabalho em Saúde" submetido à Comissão de Pesquisa da Faculdade de Odontologia e ao Comitê de Ética de Pesquisa em saúde da universidade e aprovado conforme Parecer Consubstanciado do CEP $\mathrm{n}^{\circ}$. 1.009.514.

A Faculdade de Odontologia, lócus deste estudo, iniciou, em 2005, o primeiro semestre letivo de um novo currículo do curso diurno em Odontologia, sendo que $20 \%$ da carga horária desse currículo foi destinada aos estágios curriculares, a maior parte deles a serem realizados em diferentes instâncias do $\mathrm{SUS}^{14}$. A primeira turma de estudantes de Odontologia com este formato de currículo formou-se em $2009^{15}$.

Os estágios com maior carga horária de inserção no SUS são: o "Estágio Curricular Supervisionado I da Odontologia" (ECS I) e o
Estágio Curricular Supervisionado II da Odontologia (ECS II), cada um deles com 465 horas, a serem cursados no nono e décimo semestre do curso, respectivamente. No ECS I, os estudantes atuam nos serviços de Atenção Primária à Saúde do município de Porto Alegre e região metropolitana, supervisionados por CD preceptores. No ECS II, a formação ocorre em Centros de Especialidades Odontológicas (CEO), Hospitais, Serviços de Urgência e Emergência e na Gestão Municipal e Estadual de Saúde. Além disso, os estudantes têm atividades coletivas semanais na faculdade orientados por professores em atividades como seminários, rodas de discussões, aulas expositivas e tutoria. No ECS I, as experiências de planejamento de ações, estudo de caso familiar e territorialização são apresentadas pelos estudantes ao final de cada semestre com a participação do grupo de preceptoria, constituindo-se em um momento de troca entres todos os participantes ${ }^{16}$.

O estudo compreendeu 341 egressos do curso de Odontologia, que vivenciaram os ECS no período de 2012 a 2016 e receberam o convite para participarem do estudo via endereço eletrônico fornecido pela coordenação do curso. Os dados foram coletados de 2014 a 2017. Destes egressos, 133 aceitaram participar da pesquisa após conhecerem seus objetivos e concordarem com o Termo de Consentimento Livre e Esclarecido. A taxa de resposta à pesquisa foi de $39 \%$. A inclusão dos egressos considerou terem no mínimo um ano e no máximo três anos de formado.

Os dados de um questionário com 28 questões fechadas e 4 questões abertas, enviado via endereço eletrônico aos egressos foram utilizados como material empírico. Também foram consultados e analisados os relatórios das vivências nos estágios em serviços de atenção primária à saúde durante a graduação daqueles egressos que responderam ao questionário e realizadas entrevistas em profundidade com no mínimo dois egressos de cada turma entre os que responderam 
ao questionário online, totalizando 14 entrevistas. Selecionou-se egressos que estão atuando tanto no SUS, quanto em setor privado, sem restrição de localidade, a fim de obter uma amostra representativa do conjunto de participantes. As entrevistas tiveram duração de 15 a 40 minutos e foram realizadas por estudante de iniciação científica na plataforma Skype seguindo um roteiro previamente discutido com a professora orientadora. Estas entrevistas foram gravadas e transcritas na íntegra, lidas e relidas.

Os questionários respondidos constituíram um banco de dados na plataforma Google Drive 2015, que foi posteriormente exportado para Microsoft Excel Versão 15.5.5. No mesmo software foram inseridos os dados obtidos nas entrevistas e relatórios analisados. $\mathrm{O}$ material quantitativo foi submetido à análise descritiva e o material qualitativo tanto do questionário, quanto das entrevistas e dos relatórios, foram codificados, agrupados por tema e interpretados por meio da análise de conteúdo temática ${ }^{17}$.

Considerando que os dados quantitativos e qualitativos são complementares, realizou-se a triangulação desses dados oriundos de métodos de coleta diferentes de forma a aumentar a confiabilidade do estudo ${ }^{18}$, a fim de compreender os significados que as experiências vividas nos ECS tiveram para os egressos. O material empírico possibilitou a construção de várias unidades de análise e neste artigo abordou-se duas delas: Características, Inserção e Escolha dos Egressos e a Construção de Competências Colaborativas. O referencial teórico de Peduzzi e Agreli (2018) ${ }^{5}$, Reeves (2016) ${ }^{9}$ e do grupo Canadian Interprofessional Health Collaborative $(2010)^{11}$ sobre o trabalho em equipe interprofissional, a educação interprofissional e as competências colaborativas serviram de aporte para análise do material empírico.

\section{RESULTADOS E DISCUSSÃO Características, Inserção e Escolha dos Egressos}

O estudo contou com a participação de 133 egressos da Faculdade de Odontologia, formados no período de 2012 a 2016, com idade média de $26 \pm 1,83$ anos e variação de 23 a 36 anos, sendo a maioria mulheres $(67,7 \%)$. A prevalência de mulheres em cursos da saúde tem sido constatada em vários estudos, sendo que na odontologia vem acontecendo desde os anos 90, conforme informação do Conselho Federal de Odontologia $(\mathrm{CFO})^{19}$.

Dos 133 participantes, 126 responderam à pergunta do questionário que deu origem à tabela 1. Dentre os respondentes, 99 atuam em Porto Alegre e região metropolitana, o que representa quase $80 \%$ da amostra. Estes achados coincidem com os resultados de outro estudo, que encontrou maior concentração de cirurgiões-dentistas nas capitais do país, mesmo que essas estejam mais saturadas de profissionais do que os municípios menores e afastados ${ }^{20}$.

Tabela 1. Local de atuação dos egressos da Faculdade de Odontologia de 2012/1 a 2016/1

\begin{tabular}{lcc}
\hline Local de Atuação & n & $\%$ \\
\hline Porto Alegre e Região Metropolitana & 99 & $78,60 \%$ \\
Interior do estado & 18 & $14,30 \%$ \\
Outro estado brasileiro & 8 & $6,30 \%$ \\
Outro país & 1 & $0,80 \%$ \\
\hline
\end{tabular}


A grande maioria dos egressos $(72,9 \%)$ estavam cursando pós-graduação quando responderam ao questionário, sendo que 12,4\% deles relataram já ter concluído o curso de pósgraduação e 13,2\% pretendem cursar futuramente. Apenas 2,3\% relataram não pretender cursar pósgraduação. Em estudo realizado com estudantes do curso de odontologia da Universidade Federal da Paraíba, a maioria dos estudantes demonstrou intenção de cursar pós-graduação, mesmo sem ainda sequer exercer a atividade como profissionais $^{21}$.
A maior parte dos egressos trabalha em consultório privado de outro CD $(52,8 \%)$ e apenas $18,10 \%$ deles tem o seu próprio consultório. Isto demonstra a dificuldade do CD manter propriedade sobre os seus instrumentos de trabalho, como é típico da prática liberal, o que leva o recémformado a se submeter a condições precárias de trabalho para iniciar sua atuação profissional ${ }^{22}$. Na segunda posição ficam aqueles que estão empregados na rede pública de saúde $(29,1 \%)$, conforme figura 1 .

Figura 1. Locais de inserção profissional dos egressos da Faculdade de Odontologia de 2012/1 a 2016/1

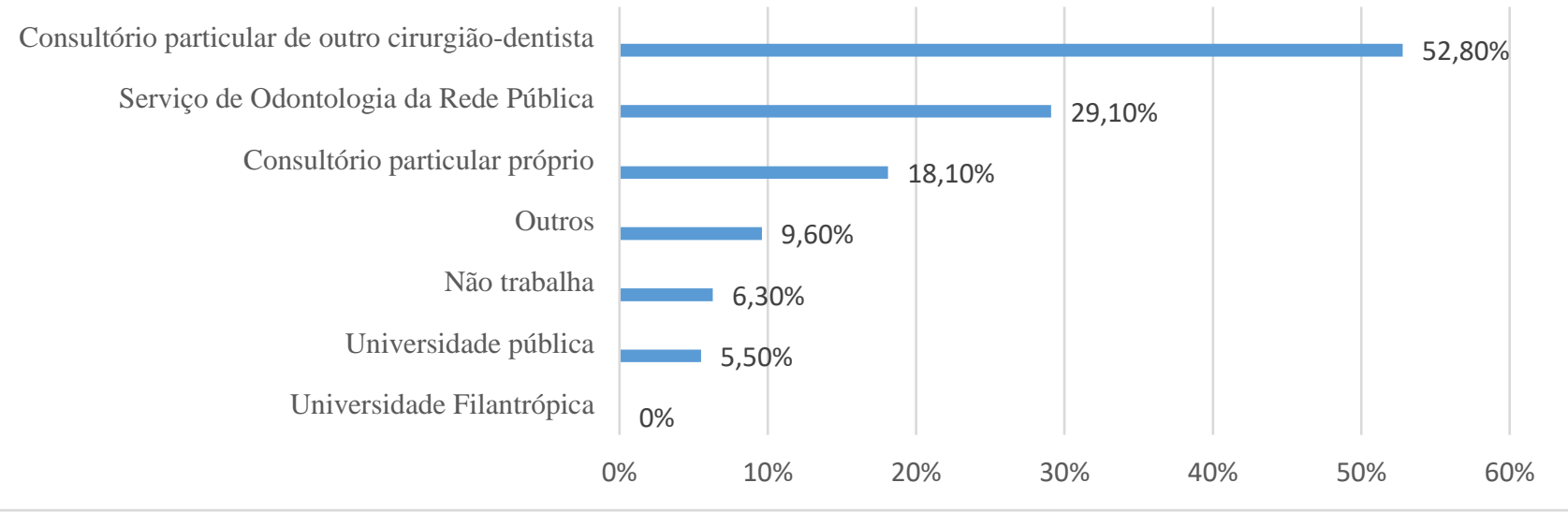

Segundo dados do CFO de 2009, mesmo com o crescimento de $49 \%$ no número de $\mathrm{CD}$ ligados ao SUS entre 2002 e 2009, o número total de empregados pelo sistema era de 40.250 profissionais, o que representava cerca de $18 \%$ do número de inscritos no Conselho ${ }^{23}$. A inserção de egressos participantes deste estudo no SUS $(29,1 \%)$ está acima da média informada pelo CFO. Presumese que este fato é relacionado ao currículo do curso de graduação e a presença de estágios curriculares com carga horária expressiva dentro do SUS.

Estudo realizado em 2011, que comparou egressos do curso de odontologia formados antes e depois da alteração curricular na mesma faculdade deste estudo, observou um maior interesse de profissionais do atual currículo no serviço público. Nesse estudo, apenas $1 \%$ dos egressos do currículo antigo queriam trabalhar exclusivamente no serviço público, porcentagem que aumentou para $8,9 \%$ entre os egressos do atual currículo. Além disso, 44,6\% dos egressos do currículo atual aceitariam trabalhar tanto no serviço público quanto no privado ${ }^{24}$.

Em outubro de 2000, as ESB foram incluídas no Programa de Saúde da Família (PSF), atualmente Estratégia de Saúde da Família (ESF). Houve, então, um planejamento estratégico da implantação dos serviços de odontologia a partir da 
análise situacional da população, em especial após o levantamento de saúde bucal (SB Brasil), em 2003. Os crescentes incentivos federais para ampliação dos serviços odontológicos, aliados as mudanças curriculares propostas pelas DCN, abriram um campo de trabalho novo e atrativo para os $\mathrm{CD}$, principalmente se considerarmos os incentivos dos Governos Lula, quando o Programa Brasil Sorridente, juntamente com o Serviço de Atendimento Móvel de Urgência (SAMU) e a Farmácia Popular, foram priorizados pelo Ministério da Saúde ${ }^{25}$.

Os incentivos do Ministério da Educação em conjunto com o Ministério da Saúde, por meio de programas como PET-Saúde, Pró-Saúde e as Residências Multiprofissionais em Saúde também buscavam desenvolver competências para atuação profissional de acordo com as necessidades do SUS. O Pró-Saúde, por exemplo, buscou desde 2005 criar modelos de reorientação da formação profissional em saúde desafiando os cursos de graduação à proporem projetos interprofissionais ${ }^{26}$.

A Faculdade de Odontologia, por meio de seus gestores, docentes, técnicos e discentes de graduação e pós-graduação, aderiu as iniciativas de reorientação da formação juntamente com outras faculdades da área da saúde e destacou-se nos programas que envolveram integração ensinoserviço-comunidade em parceria com a Secretaria Municipal de Saúde, na cidade de Porto Alegre. Entre eles, destacam-se a criação da Coordenadoria da Saúde, Disciplina Integradora em Saúde, PróSaúde I e II, PET-Saúde e Residência em Odontologia $^{27,28}$. Embora, a residência desenvolvida desde 2017 seja uniprofissional, a formação dos residentes ocorre na perspectiva do trabalho interprofissional nos serviços de saúde. Todas estas iniciativas fomentam a futura inserção dos egressos no SUS e a integração ensino-serviçocomunidade $^{27,28}$.

As escolhas dos locais de trabalho pelos egressos aconteceram predominantemente por conforto financeiro (45,7\%), seguido de possibilidade de trabalhar em equipe multiprofissional $(31,9 \%)$, o que mostra o quão interessante, inclusive financeiramente, o SUS têm se tornado para os profissionais de saúde. Em Porto Alegre, apesar da ampliação da rede de atenção básica ter ocorrido, entre 2011 e 2015, houve um crescimento expressivo de cerca de $700 \%$ na cobertura de serviços de odontologia pelo SUS, passando de 17 para 131 o número de ESB no município ${ }^{29}$.

Analisando os planos de ensino dos ECS, observa-se que estão de acordo com as Diretrizes dos Estágios Curriculares da Associação Brasileira de Ensino Odontológico (ABENO), respeitando as 12 diretrizes propostas e revisadas ${ }^{30}$. Assim, são ofertados estágios nos três níveis de atenção e em gestão ${ }^{15}$, sendo o ECS I realizado em sua maioria (66,7\%) em UBS com ESF, em 2017.

O reconhecimento do ECS I pelos egressos é alcançado pela multiplicidade de atividades executadas pelos estudantes conforme relatórios de vivência, que além de realizarem atendimentos clínicos junto de um CD preceptor, fazem visitas domiciliares, participam de campanhas de saúde, grupos de educação em saúde, reuniões de equipe, processos de gestão da unidade e são, semanalmente, convidados a refletir sobre $\mathrm{o}$ cotidiano do trabalho e trocar experiências com seus colegas em atividades presenciais com docentes na faculdade. Os estudantes também produzem um relatório de estágio enriquecido com: os registros dos diários de campo, o estudo de caso familiar, a territorialização e o planejamento de uma ação. O planejamento da ação visa trabalhar com alguma demanda específica da equipe e/ou da população do território da UBS, o que exige habilidades dos estudantes para perceber as necessidades, pensar nas possibilidades de ação, envolver e liderar a equipe em torno de uma proposta de intervenção.

No décimo semestre, os cenários de prática 
do ECS II são a Atenção Secundária e Terciária, Serviços de Urgência e Emergência e Gestão em Saúde. Para oportunizar diferentes vivências aos estudantes são disponibilizados inúmeros campos de estágio, sendo que cada estudante fica em um campo de gestão e outros serviços de atenção à saúde. Nesse semestre são realizados um Projeto Terapêutico Singular e um Projeto de Ação em Gestão, para estimular a troca de experiências entre os estudantes, possibilitando que todos visualizem o que é trabalhado em cada campo de estágio ${ }^{15}$. Cabe ressaltar que vários campos de estágio, frequentados pelos estudantes de nono e décimo semestre do curso de Odontologia, contam com preceptores formados pelo atual currículo da Faculdade de Odontologia, o que facilita o acompanhamento da proposta do estágio.

Haja visto as experiências proporcionadas pelos ECS, é possível entender o motivo pelo qual a influência dos mesmos sobre suas escolhas profissionais foi apontada por $72,4 \%$ dos egressos, em consenso com o que escreveram nos relatórios do ECS I quando fizeram a graduação.

[...] O estágio I foi meu melhor momento na graduação, fundamental para a minha escolha em cursar residência em saúde coletiva [...]. Questionário CD102, 2014/2.

[...] Enriqueci na construção do meu futuro profissional [...] Tive a oportunidade de vivenciar a rotina da saúde coletiva, de aprender o que é SUS e a Atenção Primária na prática, o que despertou em mim a vontade de fazer parte disto no meu futuro, de ajudar a melhorar, a construir. [...] Relatório CD59, 2014/1.

A experiência do estágio possibilita uma vivência concreta da realidade que o estudante vai encontrar na sua vida profissional, e por isso é decisiva para o rumo que o egresso vai tomar ao ingressar no mercado de trabalho ${ }^{31}$. Mesmo os egressos que não estão inseridos no serviço público afirmam a importância dos estágios na sua formação profissional.

[...] Os estágios curriculares supervisionados em serviços de saúde tiveram influência na minha escolha profissional de modo que pude conhecer melhor o trabalho dos serviços de saúde do SUS e seus usuários. Não quer dizer que, por não ter escolhido seguir trabalhar na rede pública até esse momento, que tenha me influenciado negativamente. Acredito que foram experiências indispensáveis na minha formação. [...] Questionário CD16, 2012/2.

Dentre os egressos, que atuam na rede pública $(29,1 \%)$, predomina a inserção em Unidades Básicas de Saúde (UBS) com ou sem ESF ( $80 \%$ dos egressos), em detrimento aos níveis secundário (7,5\% em CEOs) e terciário $(12,5 \%$ em Hospitais) de atenção à saúde.

Considera-se que o currículo vigente tem obtido sucesso ao levar o estudante de odontologia para dentro das comunidades e dos serviços da rede pública de saúde. Ao promover o contato direto com as equipes de saúde na atenção primária, secundária e terciária e em gestão, os estágios propiciam a construção de identidade com o SUS, refletindo diretamente na escolha profissional dos egressos, visto que abre um leque de oportunidades até então não imaginadas.

[...]Vi que eu não tinha muito perfil para essa coisa mais dura, de só ficar na clínica. Eu queria trabalhar a saúde para além disso. A possibilidade seria trabalhar no serviço público, que antes realmente eu não teria conhecido, não teria escolhido[...] Entrevista CD48, 2013/1.

Entre os objetivos do curso de Odontologia está "a formação de um CD generalista, com uma visão social da realidade, e capaz de estabelecer científica e tecnicamente um diagnóstico do estado de saúde bucal de cada indivíduo e da

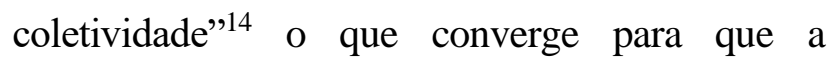


formação esteja inserida nos serviços do SUS. Outro objetivo do curso de Odontologia é que os acadêmicos devem "participar da formulação, execução e avaliação de ações, programas e políticas de saúde e assumir uma postura crítica à política sanitária da região e do país, oferecendo alternativas que respondam às demandas sociais"14. Os ditos dos egressos corroboram o papel dos estágios para atingir os objetivos do curso.

\section{Construção de Competências Colaborativas}

Entre as habilidades a serem desenvolvidas na formação profissional destaca-se a capacidade de "saber pensar", o que muitas vezes se confunde com o saber fazer. A mente humana não trabalha diretamente com a realidade, mas sim a constrói de modo autorreferente, por isso a importância da prática dentro dos currículos acadêmicos. Além disso, quando o estudante está diretamente em contato com a prática e com pessoas que a vivem, é possível que sejam desenvolvidas habilidades através da aprendizagem não formal, que muitas vezes podem ser até mais adequadas que aquelas aprendidas formalmente (em instituições acadêmicas) $)^{32}$. A importância da vivência prática dentro dos serviços de saúde para a formação dos estudantes ficou marcada nos relatórios executados durante a graduação.

[...] A oportunidade de vivenciar a Atenção Básica na prática simplificou e tornou compreensível os conceitos trabalhados em inúmeras disciplinas da Saúde Coletiva. Isso proporcionou não apenas a nós, mas a muitos colegas, desmistificar a atuação do cirurgião-dentista na saúde pública[...] Relatório Dupla CD 9 e 21, 2012/2

[...] Hoje me sinto muito mais preparada no sentido de uma melhor habilidade $e$ qualidade técnica, mais segurança $e$ melhor relação profissional-paciente. Além de profissional também ganhei muito crescimento pessoal. $O$ entendimento do que é saúde pública, não poderia ter sido só através de leituras. Foi ali no dia a dia [...] Relatório CD 99, 2014/1.

$\mathrm{Na}$ visão dos egressos, dentre as competências para o trabalho em saúde estimuladas pelas experiências dos estágios no SUS, destacam-se as competências colaborativas para trabalhar em equipe, conforme figura 2.

Figura 2. Competências para o trabalho em saúde estimuladas pelas experiências dos ECS no SUS

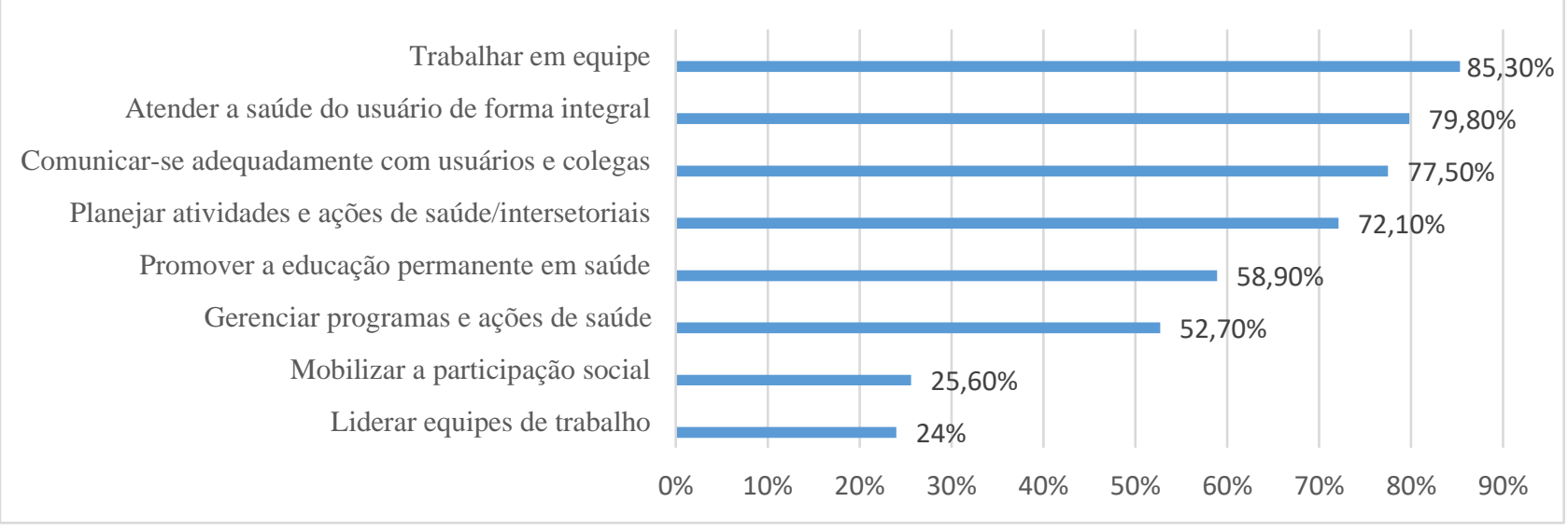

$\mathrm{Na}$ área da saúde, vários autores discutiram requisitos para que o trabalho em equipe de saúde resulte em atenção humanizada e integral ao usuário. Entre estes, destacam-se Peduzzi e Agreli (2018) $)^{5}$, que definem o trabalho em equipe interprofissional como "aquele que 
envolve diferentes profissionais, não apenas da saúde, que junto compartilham o senso de pertencimento à equipe e trabalham juntos de maneira integrada e interdependente para atender às necessidades de saúde". Nessa perspectiva, espera-se que o egresso tenha a capacidade de trabalhar com vários profissionais e de diversas profissões e assumir papel de liderança dentro das equipes de saúde, sendo comunicativo e mediando conflitos internos. Estas competências podem ser alcançadas, caso haja oportunidades concretas durante a formação ${ }^{9,32}$, que neste caso são ofertadas especialmente no currículo por meio dos ECS como apontado pelos egressos nos relatórios durante a formação e nas entrevistas após formados:

[...] O PSE foi meu objeto de estudo. Tudo isso foi coordenado por mim e pela residente do posto. [...] Teve essa questão de tomar a frente de alguma coisa, que foi uma experiência muito legal [...] Entrevista CD 112, 2015/2.

[...] Dentre minhas atividades semanais realizei procedimentos clínicos, visitas domiciliares, participei de reuniões de equipe $e$ atividades coletivas de educação, além de reuniões do Conselho Local de Saúde. Todas essas atividades fortaleceram minha formação universitária, do entendimento técnico ao trabalho em grupo e liderança. [...] Relatório CD 2, 2014/1.

[...] Aprendemos a lidar com as diferenças entre os colegas, onde devemos saber ser críticos na medida certa para não aceitar as coisas sem criticar, mas também não nos desentendermos com eles. Relatório CD 69, 2014/1.

O desenvolvimento de diversas competências durante a formação, o que inclui as competências colaborativas citadas pelos egressos - atendimento centrado no paciente, entendimento dos papéis profissionais, capacidade de liderança, comunicação e resolução de conflitos - é imprescindível para possibilitar a reflexão crítica e facilitar a construção de respostas frente as exigências impostas no dia a dia do trabalho em saúde ${ }^{33}$.

Nesse contexto, os ECS têm se mostrado efetivos para o entendimento de como se dá a atuação em equipes multiprofissionais, visto que essa é uma competência que só pode ser aprendida na prática e requer interação com outros profissionais como os egressos apontaram nas entrevistas.

[...] A gente aprende (a trabalhar em equipe) só na vivência no campo. Porque de resto a gente não tem nada que ensine, trabalho em equipe é uma coisa que se aprende na prática. [...] Entrevista CD9, 2012/2.

[...] Nos estágios eu consegui me enxergar como um profissional da saúde para além da saúde bucal. Eu lembro que isso me marcou bastante: todos os profissionais estarem discutindo todos os casos, de ver aquela família, não ver só aquela pessoa, aquela boca, aquele dente [...] Entrevista CD48, 2013/1.

Algumas fragilidades são apontadas na formação desenvolvida dentro dos serviços no contexto analisado, entre elas: a rotatividade dos profissionais de saúde nos serviços, que recebem os estudantes, devido aos contratos de trabalho provisórios, tem sido uma marca cíclica na vulnerabilidade programática dos estágios, interrompendo o vínculo entre estudante-tutorpreceptor, o que as vezes é minimizado pela interação com a equipe. No ECS II, a ociosidade de alguns serviços de atenção secundária devido ao absenteísmo dos usuários foi relatada pelos estudantes, visto que a experiência na APS foi intensa com os usuários, a comunidade e a equipe 
e que havia demanda reprimida pelos serviços especializados. Os participantes também apontaram que o estágio em gestão deveria ser concentrado em um mês para que o estudante pudesse entender a dinâmica do trabalho.

[...] Em relação aos CEOs, meu estágio foi muito ocioso. Acho que o estágio em gestão deveria ser de um mês corrido, pois a gestão é dinâmica e indo uma vez na semana, perdem-se diversas atividades, pois o que foi iniciado já pode ter sido concluído. Questionário CD 9, 2012/2.

Outro aspecto a considerar é se o preceptor teve na sua formação experiência interprofissional e tem disponibilidade para fomentar práticas colaborativas na equipe. A maioria dos egressos expressam satisfação em relação ao preceptor e a equipe, outros, no entanto, lamentam por terem sentido a falta delas em alguns profissionais de saúde com quem conviveram nas equipes. Porém, justamente, por entenderem que a situação vivida era pontual e específica de sua unidade, tornavam essa dificuldade um estímulo para fazerem diferente espelhando-se nos princípios éticos profissionais.

Dentro da nossa equipe existiam algumas pessoas que não queriam trabalhar, queriam simplesmente ter a garantia que o serviço público propicia [...] vi nessas atitudes um estímulo para seguir a carreira pública. Se essas pessoas não realizam suas atividades como deveriam fazer, eu vou me preparar e estudar para fazer meu papel de forma adequada e ética [...] Relatório CD67, 2014/1.

O preparo de docentes e preceptores para a EIP foi abordado em alguns estudos, que descrevem a importância de profissionais qualificados para o sucesso do sistema de saúde $^{34}$. Outros autores reforçam essa ideia, afirmando que uma força de trabalho competente tem o conhecimento e as habilidades necessárias para traduzir a teoria em política e a pesquisa em ação efetiva, constituindo elemento fundamental para o crescimento e desenvolvimento da atenção à saúde ${ }^{35}$. Concorda-se que o mesmo pode ser aplicado para o contexto dos estágios curriculares.

Os egressos de forma geral destacaram os estágios, em especial o ECS I, pelo crescimento tanto como profissional, quanto como cidadão, que lhes foi proporcionado. Estes aspectos estão presentes nos três instrumentos de produção de dados (relatórios, questionários e entrevistas). Junto dessas impressões, o trabalho em equipe interprofissional sempre é citado como um dos pontos mais importantes para a formação.

A lógica atual de facilidade de acesso às informações faz surgir a necessidade de saber pensar colaborativo. O saber pensar, portanto, não se restringe mais a uma capacidade individual, produto de cabeças privilegiadas; é uma construção coletiva, pois todos devem saber pensar e pensar juntos, ao invés de um pensar pela maioria ${ }^{27}$. Os estágios são vistos, majoritariamente, como a primeira e única oportunidade de pensar coletivamente tanto com profissionais, como com os usuários; é a chance de interagir com profissionais de diversas graduações em saúde, já que as relações se restringem a tríade estudante-usuário-professor durante a maior parte da graduação, sendo predominantemente uniprofissional. As discussões de casos são colocadas como enriquecedoras para o estudante, para a equipe e para o usuário. Nos ditos dos egressos é possível perceber o quanto a convivência em equipe é valorizada para a aprendizagem, em especial para o entendimento dos papéis profissionais, assim como possibilita o desenvolvimento da capacidade de comunicação, mediação de conflitos e ideias divergentes. 
Eu aprendi a conviver em uma equipe de trabalho, já que eu nunca tinha tido uma experiência de troca de ideias. $\mathrm{Na}$ faculdade é tu, teu paciente e o professor; não tem quem vá dar um palpite, é só o professor que é autoridade e diz se está certo ou errado e tu que obedece. Eu aprendi a conviver e discutir com outras pessoas, outras profissões, com gente que pensa diferente e gente que pensa parecido. Eu acho que o trabalho em equipe para o paciente também é essencial. [...] Entrevista CD126, 2015/2.

Os egressos consideram, por unanimidade, que as competências colaborativas são de extrema importância para a formação e para a atenção centrada no usuário na rede de saúde, como descrevem nos relatórios.

[...] É na vivência do estágio que o aluno é instigado a ver os paciente como um todo, a planejar ações de promoção e prevenção de saúde de acordo com a realidade de cada usuário, bem como aprender a fazer uso do SUS da melhor forma possível para garantir a melhora da saúde dele, seja no âmbito odontológico, de saúde geral ou em sua condição social [...] Relatório CD51, 2013/2.

A comunicação e o compartilhamento de saberes com a equipe e com os usuários, também foram destacados pelos egressos. Segundo um deles, ter tido contato com a atenção integral pela qual os usuários são acolhidos e tratados nos serviços de APS auxilia muito na sua vida profissional. É interessante que mesmo atuando em consultório particular, ele percebe ter facilidades de comunicação advindas dessas experiências.

[...] Essa percepção hoje é importante tanto pela comunicação com outros profissionais, quanto para interpretar alguns exames e verificar fatores de risco que podem pesar na decisão de se realizar uma cirurgia de implantes, por exemplo [...]. Questionário CD131, 2015/1.

O estagiário sente-se de fato parte de uma equipe e participa ativamente das reuniões. Isso, associado às atividades de discussão com colegas e docentes e a realização dos diários de campo e dos relatórios possibilitam reflexões sobre as vivências nos campos de estágio e, por conseguinte, o entendimento do papel do estagiário e do futuro profissional dentro da equipe de saúde, o que vem a somar na formação profissional dos egressos.

\section{CONSIDERAÇÕES FINAIS}

Nesse estudo, os egressos de um curso de graduação em Odontologia do sul do país definem por si mesmos as condições em que vivenciaram os estágios curriculares, que valores e sentidos a "experiência vivida" tiveram para eles. Os egressos expressam satisfação com as experiências proporcionadas pelos ECS. A maioria deles relata ter tido uma experiência enriquecedora do ponto de vista pessoal e profissional e considera as vivências nos cenários de prática do SUS indispensáveis para sua formação profissional e cidadã. Eles percebem que muitas competências são afloradas no período de estágio, sendo a capacidade de trabalhar em equipe a mais comentada delas. Os egressos apontam que durante os estágios puderam entender os papéis profissionais e das equipes no SUS, assumir papel de liderança dentro das equipes de saúde, desenvolver a capacidade de comunicação e atenção centrada no paciente, mediação de conflitos e de ideias divergentes, enquanto competências colaborativas importantes para o trabalho em saúde.

É possível perceber, que os participantes desse estudo têm uma inserção nos serviços públicos acima do percentual relatado pelo $\mathrm{CFO}$, o que pode ter relação com o envolvimento dos estudantes na esfera pública durante sua formação e que leva a quebra de preconceitos previamente estabelecidos. Também colabora para isso, a 
expansão das unidades com ESF e de outros serviços de média e alta complexidade tecnológica em odontologia, ofertados a nível nacional e, principalmente, no município de Porto Alegre, que abrem a possibilidade de inserção dos egressos nos serviços públicos de saúde.

O estudo foi realizado em uma faculdade de odontologia de universidade pública, que investe na formação em serviços públicos de saúde e, portanto, os resultados não são generalizáveis para locais, que não tenham as mesmas características. No entanto, acredita-se que mesmo em instituições de ensino privadas cabe propiciar vivências no SUS aos estudantes, não somente para atender a legislação vigente, mas por motivar a formação cidadã de profissionais de saúde, preparando-os para atuação no SUS. Por fim, recomenda-se a gestão do curso de odontologia que a perspectiva de formação dentro dos serviços do SUS seja mantida por meio de parcerias com as secretarias municipais de saúde, cumprindo assim protagonismo em seu papel de contribuição com a sociedade na atenção às demandas de usuários, gestores e profissionais das redes de saúde.

O objetivo da reforma curricular proposta pelas DCN para os cursos de odontologia tem sido profícuo na faculdade em questão, visto que os egressos valorizam o trabalho em equipe interprofissional, a integralidade e humanização do cuidado, reconhecendo sua importância para as práticas colaborativas em todos os contextos de atuação.

\section{ABSTRACT \\ Construction of collaborative skills for health work in curricular internships in Dentistry in SUS}

With the establishment of the Brazilian Unified Health System (SUS), curricular changes were necessary to prepare the professionals for teamwork in the healthcare network. In the early $21^{\text {st }}$ century, the National Curricular Guidelines (DCN) were implemented and brought several changes, mainly the insertion of undergraduate students in SUS. This study analyzed the perceptions of graduates of the daytime Dentistry course from a public university in Rio Grande do Sul about the construction of collaborative skills during training in the Supervised Curricular Internships (ECS) in SUS. This descriptive study analyzed qualitative and quantitative data. Initially, 133 graduates who experienced the ECS between 2012/1 to 2016/1 answered an online questionnaire with open and closed questions. Deeper semi-structured interviews were conducted on an intentional sample of 14 graduates who answered the questionnaire. The quantitative material was submitted to descriptive analysis and the qualitative material to thematic content analysis. Considering that quantitative and qualitative data are complementary, they were submitted to triangulation and the results are presented in two units of analysis: Characterization, insertion and professional choices of graduates; and Construction of collaborative skills. Most participating graduates $(67.7 \%)$ are females and are working in Porto Alegre or metropolitan area (78.6\%), being $29.1 \%$ inserted in public health services. The satisfaction with the ECS is highlighted by the graduates, who describe them as fundamental for their training. Among the collaborative skills built during internships, learning how to work in an interprofessional team was highlighted by most graduates $(85.3 \%)$, being remembered as fundamental for the integral care to the user. It is concluded that the Dentistry course has been successful in the training of professionals to work in SUS, with a considerable percentage of graduates inserted in public health services.

Descriptors: Community Dentistry. Education, Dental. Health Services. Skill-Based Education.

\section{REFERÊNCIAS}

1. Brasil. Constituição da República Federativa do Brasil de 1988. Brasília, DF: Presidência da República, 2016. [Acesso em: 01/01/2019]. Disponível em: http://www.planalto.gov .br/ccivil_03/Constituicao/Constituicao.htm. 
2. Brasil. Ministério da Saúde. Portaria n ${ }^{\circ} 2.436$, de 21 de setembro de 2017. Aprova a Política Nacional de Atenção Básica, estabelecendo a revisão de diretrizes para a organização da Atenção Básica, no âmbito do Sistema Único de Saúde (SUS). [Acesso em: 01/01/2019]. Disponível em: https://bvsms.saude.gov.br/ bvs/saudelegis/gm/2017/prt2436_22_09_201 7.html.

3. Morita MC; Kriger L. Mudanças nos cursos de Odontologia e a interação com o SUS. Rev ABENO. 2004; 4(1):17-21.

4. Brasil. Ministério da Educação. Conselho Nacional de Educação. Câmara de Educação Superior. Resolução CNE/CES n.3, de 19 de fevereiro de 2002. Institui Diretrizes Curriculares Nacionais do Curso de Graduação em Odontologia. [Acesso em: 01/01/2019]. Disponível em:

http://portal.mec.gov. br/cne/arquivos/pdf/CES032002.pdf.

5. Peduzzi M; Agreli HF. Trabalho em equipe e prática colaborativa na Atenção Primária à Saúde. Interface. 2018; 22(2):1525-34.

6. Rossoni E. Residência na atenção básica à saúde em tempos líquidos. Physis. 2015; 25(3):1011-31.

7. Organização Mundial da Saúde. Marco para ação em educação interprofissional e prática colaborativa. Genebra, 2010. [Acesso em: 01/01/2019]. Disponível em: http://new. paho.org/bra/images/stories/documentos/mar co_para_acao.pdf.

8. Reeves S. Porque precisamos da educação interprofissional para um cuidado efetivo e seguro. Interface. 2016; 20(56):185-96.

9. Tsuji H; Aguilar-da-Silva RH. Aprender e ensinar na escola vestida de branco: do modelo biomédico ao humanístico. São Paulo: Phorte, 2010.

10. Canadian Interprofessional Health Collaborative. A National Interprofessional Competence Framework. Consortium pancanadien pour l'interprofessionnalisme en santé. Vancouver, 2010, p. 8.

11. Silva JAM, Peduzzi M, Orchard C, Leonello S. Educação interprofissional e prática colaborativa na Atenção Primária à Saúde.
Rev Esc Enferm USP. 2015; 49(2):16-24.

12. Anderson E, Thorpe L, Heney D, Petersen S. Medical students benefit from learning about patient safety in an interprofessional team. Med Educ. 2009; 43(6):542-552.

13. Matos MS, Tenório R. Percepção de alunos, professores e usuários acerca da dimensão ética na formação de graduandos de odontologia. Cienc Saúde Coletiva. 2010; 15(2):3255-64.

14. Porto Alegre. Projeto Político-pedagógico. Faculdade de Odontologia, Universidade Federal do Rio Grande do Sul, 2005, 43p. [Acesso em: 01/01/2019]. Disponível em: http://www.ufrgs.br/odonto/projeto_pedagogi co_odontologia curso_diurno.

15. Warmling CM, Rossoni E, Hugo FN, Toassi RFC, Lemos VA, Slavutzki SMB, Bercht S, Nunes AA, Rosa AR. Estágios curriculares no SUS: experiências da Faculdade de Odontologia da UFRGS. Rev ABENO. 2011; 11(2):63-70.

16. Rossoni E, Stocker JR, Cardoso W, Sasso ELM. Percurso formativo de egressos de odontologia nos estágios curriculares no Sistema Único de Saúde. In: Anais da 52a Reunião Anual da Associação Brasileira de Ensino Odontológico. Rev ABENO. 2017; 17(1): 180 .

17. Bardin 1. Análise de Conteúdo. Lisboa: Edições 70, 2009.

18. Gray DE. Pesquisa no Mundo Real. $2^{\mathrm{a}}$ ed. Porto Alegre: Penso, 2012, 488p.

19. Morita, MC, Haddad AE. Interfaces da área de educação e da saúde na perspectiva da formação e do trabalho das equipes de saúde da família. In: Moysés ST, Kriger L, Moysés SJ. (Orgs). Saúde bucal das famílias: trabalhando com evidências. São Paulo: Artes Médicas, 2008; p. 268-76.

20. Rezende FP. Perfil, motivações e expectativas dos graduandos e graduados em odontologia. Rev Odontol UNICID. 2007; 19(2):165-72.

21. Machado FC, Souto DMA, Freitas CHSM, Forte FDS. Odontologia como escolha: perfil de graduandos e perspectiva para o futuro profissional. Rev ABENO. 2010; 10(2):27-34. 22. Moraes DA, Maluf F, Tauil PL, Portillo JAC. 
Precarização do trabalho odontológico na saúde suplementar: uma análise bioética. Cienc Saúde Coletiva. 2019; 24(3):705-14.

23. Conselho Federal de Odontologia. Número de CDs no SUS cresce 49\%. Brasília, 2010. [Acesso em: 01/01/2019]. Disponível em: http://cfo.org.br/todas-as-noticias/noticias/ numero-de-cds-no-sus-cresce-49/.

24. Junges R, Stello RS, Portella FF, Rösing CK, Samuel SMW. Impact of the implantation of a new curriculum in the process of learning in a Faculty of Dentistry in Brazil. Braz Oral Res]. 2011; 25(6):478-84.

25. Machado CV; Baptista TWF; Nogueira CO. Políticas de saúde no Brasil nos anos 2000: a agenda federal de prioridades. Cad Saúde Pública. 2011; 27(3):521-32.

26. Rossoni E. Integralidade, educação permanente e trabalho em equipe: multiplicando sentidos na formação em saúde. Bole Saúde. 2016; 25(1):35-49.

27. Machado MH, Ximenes Neto FRG. Gestão da Educação e do Trabalho em Saúde no SUS: trinta anos de avanços e desafios. Cienc Saúde Coletiva. 2018; 23(5):1971-80.

28. Tompsen NN, Meireles E, Peduzzi M, Toassi RFC. Educação interprofissional na graduação em Odontologia: experiências curriculares e disponibilidade de estudantes. Rev Odontol UNESP. 2018; 47(5): 309-20.

29. Porto Alegre. Prefeitura Municipal. Saúde bucal amplia serviços de atendimento à população. Porto Alegre, 2015. [Acesso em: 01/01/2019]. Disponível em: http://www2. portoalegre.rs.gov.br/sms/default.php?p_notic $\mathrm{ia}=178187 \&$ SAUDE+BUCAL+AMPLIA+S ERVICOS+DE+ATENDIMENTO+A+POP ULACAO.
30. Scavuzzi AIF, Gouveia CVD, Carcereri DL, Veeck EB, Ranali J, Costa LJ, Morita MC, Araujo, ME. Revisão das Diretrizes da ABENO para a definição do estágio Supervisionado Curricular nos cursos de Odontologia. Rev ABENO. 2015; 15(3):10913.

31. Toassi RFC, Davoglio RS, Lemos VMA. Integração ensino-serviço-comunidade: o estágio na Atenção Básica da graduação em Odontologia. Educ Rev. 2012; 28(4):223-42.

32. Demo P. Habilidades e competências no Século XXI. 3. ed. Porto Alegre: Mediação, 2012. $104 \mathrm{p}$.

33. Lima AWS, Alves FAP, Linhares FMP, Costa MV, Marinus-Coriolano MWL, Lima LS. Percepção e manifestação de competências colaborativas em discentes da graduação em saúde. Rev Latino Am Enf. 2020; 28: e3240.

34. Lilley KC, Stewart DE. The Australian preventive health agenda: what will this mean for workforce development? Australia \& New Zealand Health Policy. Collingwood, 2009; 1(6):14.

35. Battel-Kirk B, Barry MM, Taub A, Lysoby L. A review of the international literature on health promotion competencies: identifying frameworks and core competencies. Global Health Promotion, 2009; 16(2):12-20.

\section{Correspondência para: \\ Eloá Rossoni \\ e-mail: rosssonieloa@gmail.com \\ Rua Pedro Souza, 156 \\ 91520-130 Porto Alegre/RS}

